\title{
EVAPORATION RATE OF A LIQUID LAYER STREAMLINED BY GAS FLOW IN MINICHANNEL
}

\author{
Evgeniya G. Orlova ${ }^{1 *}$, Anastasia G. Islamova ${ }^{1}$, and Oleg A. Kabov ${ }^{2}$ \\ ${ }^{1}$ Tomsk Polytechnic University, 634050, Tomsk, Russia \\ ${ }^{2}$ Kutateladze Institute of Thermophysics, 630090, Novosibirsk, Russia
}

\begin{abstract}
Paper presents the experimental results of mass evaporation rate from ethanol layer surface into a moving in parallel way air flow. Dependences of the mass evaporation rate on the gas velocity, temperature difference between gas and liquid layer, and liquid layer thickness were obtained. The assumption about the formation of the concentration boundary layer at the interface was made. It is found that with increasing the gas flow velocity the gradient of vapor concentration in the gas phase increases; as a result the evaporation rate rises. When changing the liquid layer thickness, the local maximum of evaporation rate was observed, but for $2 \mathrm{~mm}$ thickness layer two maxima were found. Probably, it is due the appearance of unstable structures on the liquid surface.
\end{abstract}

\section{Introduction}

Recently cooling systems with mini- and microchannels [1-3] are widely used in the microelectronic equipment and aerospace machines. It is connected with the fact that their application significantly reduces the coolant flow rate [4-9]. To intensify heat exchange in thermal control systems with motion of the coolant in minichannels, it is possible to use gas flow streamlining the liquid surface. In this case, the evaporation rate from the interface will depend not only on the velocity and thickness of the liquid, its temperature, but also on the velocity and temperature of gas flow.

Study of the interface formed at streamlining of the liquid layer by the gas flow is a complex problem. In this case, it is necessary to take into account simultaneously such transfer mechanisms as forced and natural convection, thermocapillary convection, diffusion [10-17].

According to analyses of previous studies devoted to this subject [10-21] a significant lack of experimental studies taking into account the evaporation is found out. The majority of works were devoted to the study of hydrodynamics and the emergence of various instabilities at the interface. The purpose of this work is to study experimentally the influence of gas velocity, temperature difference between gas and liquid layer, liquid layer thickness on the evaporation rate from the liquid/gas interface.

\footnotetext{
*Corresponding author: lafleur@tpu.ru
} 


\section{Experimental apparatus}

The research was conducted on the experimental setup with stationary layer of ethanol streamlined by the air flow in the test cell (Fig. 1). The principle of operation is described in detail in [1]. To maintain a constant level of evaporating liquid layer in the evaporation zone, a peristaltic pump was used. The gas temperature was controlled with distilled water heated in a thermostatic bath and circulating through the channels of the test cell case. A thermoelectric module provided the necessary temperature of the liquid. The position of the interphase presented in Fig.1 was controlled by the shadow method through the optical window.

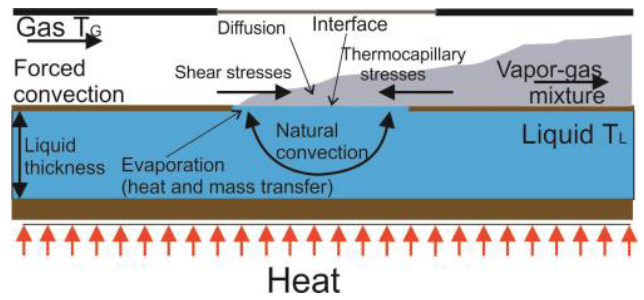

Fig. 1. Schematic representation of the experimental conception.

The test cell consists of the liquid chamber with $40 \mathrm{~mm}$ in width and variable height from 1 to $10 \mathrm{~mm}$ and rectangular gas channel $19(3 \mathrm{~mm}$ in height, $40 \mathrm{~mm}$ in width, $150 \mathrm{~mm}$ in length). The upper wall of the liquid has a square opening where liquid and gas are in contact. The gas flow rate at the inlet of the test cell was varied from $0.0139 \mathrm{~m} / \mathrm{s}$ to 0.1389 $\mathrm{m} / \mathrm{s}$. The gas temperature was constant $\left(25^{\circ} \mathrm{C}\right)$, and the values of liquid temperature were $15,20,25,30$, and $35^{\circ} \mathrm{C}$. The interface area was constant $\left(100 \mathrm{~mm}^{2}\right)$. The values of liquid layer thickness were $1,2,3,4,5$, and $8 \mathrm{~mm}$. The evaporation rate from the liquid layer surface was defined by measuring the difference between mass flow rate of gas (air) at the inlet of the test cell and air-coolant vapours mixture at the outlet.

\section{Results and discussion}

According to results of conducted experiments the mass evaporation rate is found to increase at increase in the temperature difference between liquid layer and moving in parallel way the gas flow $\Delta T=T_{L}-T_{G}$ (Fig.2).

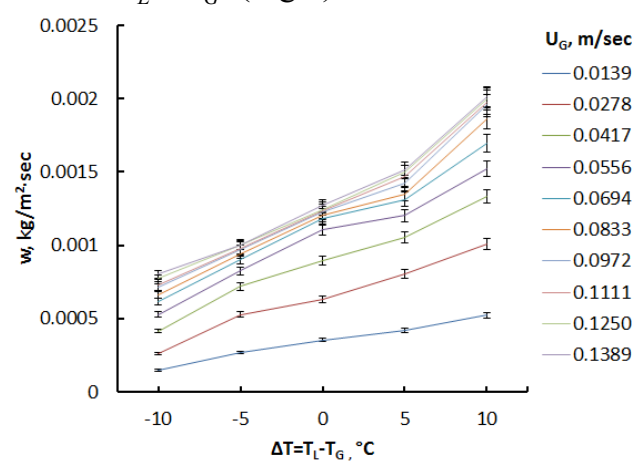

Fig. 2. Mass evaporation rate versus temperature difference $\Delta T=T_{L}-T_{G}$. Liquid layer thickness is $\mathrm{h}=1 \mathrm{~mm}$. 
The difference between the temperature of the liquid and gas does not influence the power form of the growth curves of the evaporation rate. The mass evaporation rate increases monotonically for all thicknesses of the layer. It can be explained by the fact that the vapor concentration near the liquid/gas interface corresponds to the saturated vapor pressure at the interface temperature and increases with increasing the liquid temperature. Also with an increase in the liquid temperature the average kinetic energy of the liquid molecules increases. Thus, the numbers of molecules with sufficiently large kinetic energy to pass to the evaporation zone increase.

Dependences of the mass evaporation rate on the liquid layer thickness are shown in Fig. 3.

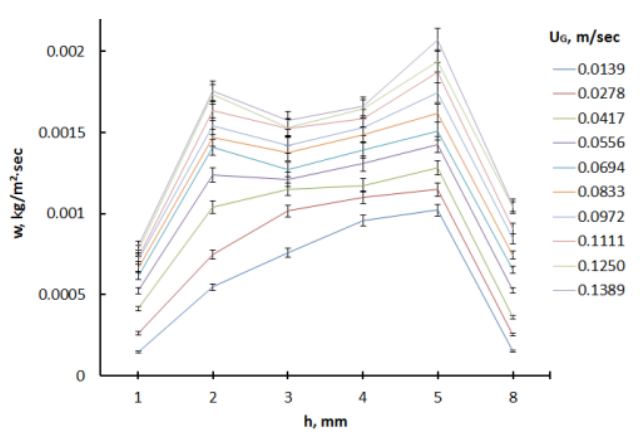

Fig. 3. Mass evaporation rate versus liquid layer thickness. Temperature difference is $\Delta T=-10^{\circ} \mathrm{C}$.

With increasing layer thickness of the evaporating liquid the local maximum of the evaporation rate, which depends on the gas flow rate, was observed. It should be noted that the maximum of the evaporation rate from $5 \mathrm{~mm}$ thickness liquid layer was observed for all dependences (Fig. 3). In addition, the evaporation rate from $5 \mathrm{~mm}$ thickness liquid layer increases by $35 \%$ compared to the $4 \mathrm{~mm}$ thickness. However, when the gas flow rates range from 0.0556 to $0.1389 \mathrm{~m} / \mathrm{sec}$, another maximum can be observed at a layer thickness of 2 $\mathrm{mm}$. It can be connected with a liquid layer instability, which in turn causes an increase in the evaporation rate.

The mass evaporation rate is found to increase with an increase in the gas flow velocity (Fig. 4.).

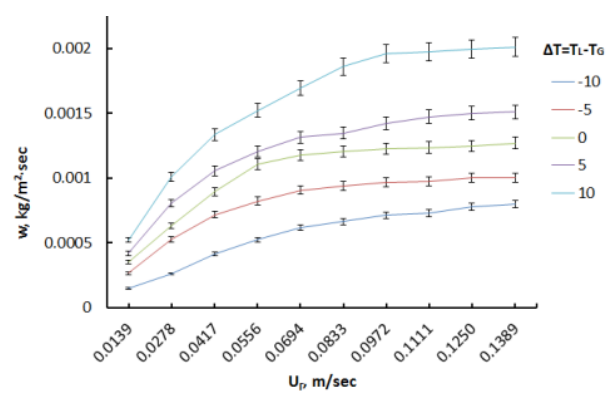

Fig. 4. Mass evaporation rate versus gas flow velocity. Liquid layer thickness is $\mathrm{h}=1 \mathrm{~mm}$.

It can be explained by the fact that the vapor forming above the interfacial surface is removed in the channel by the gas flow. Alcohol vapors are moved from the liquid/gas interface due to forced convection and diffusion. Thus, the evaporation rate increases with increasing gas flow velocity due to an increase in the concentration gradient of the gas phase.

The range of the gas flow velocity from 0.0139 to $0.0694 \mathrm{~m} / \mathrm{sec}$ should be pointed out because the mass evaporation rate increases dramatically in this range. It is due to the 
relatively low velocities of alcohol vapors removal in the gas phase. With further increase in the gas velocity the removal of vapors becomes more intensive; as a result the evaporation rate growth reduces.

It is also found that the mass evaporation rate increases sharply by $25 \%$ for the entire range of the liquid layer thickness when the temperature difference is $10^{\circ} \mathrm{C}$. When the liquid temperature increases, there is an imbalance of forces during evaporation process. The influence of convection in the liquid layer amplifies, liquid is mixed more intensive, and also with an increase in the liquid temperature the numbers of molecules capable of leaving the free path area and passing to the evaporation zone increase.

The reported study was supported by RFBR, research project No. 16-38-50220 mol_nr. The Schlieren optical system was elaborated under the support of Russian Science Foundation (Agreement No. 14-19-01755).

\section{References}

1. Y. Lyulin, D. Feoktistov, I. Afanas'ev, E. Chachilo, O. Kabov, G. Kuznetsov, Tech. Phys. Lett., 41, 665 (2015)

2. D. Zaitsev, D. Rodionov, O. Kabov, Tech. Phys. Let., 35, 680 (2009)

3. O. Kabov, D. Zaitsev, Multiphase Sci. Technol., 21, 249 (2009)

4. A. Sivkov, A. Saygash, J. Kolganova, I. Shanenkov, IOP Conf. Ser.: Mater. Sci. Eng., 66, 012001 (2014)

5. A. Sivkov, Y. Shanenkova, A. Saigash, I. Shanenkov, Surf. Coat. Technol., 292, 63 (2016)

6. D. Glushkov, J. Legros, P. Strizhak, A. Zakharevich, Fuel, 175, 105 (2016)

7. D. Glushkov, G. Kuznetsov, P. Strizhak, R. Volkov, Therm. Sci., 20, 131 (2016)

8. D. Glushkov, G. Kuznetsov, P. Strizhak, Therm. Sci., 19, 1541 (2015)

9. G. Kuznetsov, A. Zakharevich, N. Bel'kov, Chem. Pet. Eng., 50, 424 (2014)

10. V. Maksimov, T. Nagornova, EPJ Web of Conf., 76, 01006 (2014)

11. K. Batischeva, E. Orlova, D. Feoktistov, MATEC Web of Conf., 19, 01001 (2014)

12. E. Orlova, D. Feoktistov, G. Kuznetsov, EPJ Web of Conf., 82, 01053 (2015)

13. V. Nakoryakov, S. Misyura, S. Elistratov, A. Manakov, A. Sizikov, J. Eng. Thermophys., 22, 169 (2013)

14. V. Lebedev, V. Lemanov, S. Misyura, V. Terekhov, Fluid Dyn., 28, 624 (1993)

15. V. Nakoryakov, S. Misyura, S. Elistratov, R. Dekhtyar, J. Eng. Thermophys., 23, 257 (2014)

16. D. Feoktistov, E. Orlova, A. Islamova, EPJ Web of Conf., 110, 01018 (2016)

17. K. Ponomarev, E. Orlova, D. Feoktistov, EPJ Web of Conf., 110, 01060 (2016)

18. R. Volkov, G. Kuznetsov, P. Strizhak, Thermophysics and Aeromechanics, 21, 255 (2014)

19. O. Vysokomornaya, G. Kuznetsov, P. Strizhak, J. Eng. Phys. Thermophys, 86, 62 (2013)

20. G. Kuznetsov, M. Sheremet, Fluid Dyn., 41, 881 (2006)

21. E. Orlova, G. Kuznetsov, D. Feoktistov, EPJ Web of Conf., 76, 01039 (2014)

22. G. Kuznetsov, P. Kuybin, P. Strizhak, High Temp., 53, 254 (2015) 